\title{
Adjuvant nodal radiation therapy for malignant melanoma with single region nodal metastasis
}

\author{
Jennifer Sherriff • Agustin Martin-Clavijo • \\ Peter Nightingale $\cdot$ Anjali Zarkar
}

Received: 11 June 2012 / Accepted: 13 August 2012 /Published online: 29 August 2012

(C) Springer-Verlag 2012

\begin{abstract}
Objective Adjuvant radiation therapy (RT) is increasingly used following lymph node block dissection for regional recurrence/metastasis of malignant melanoma. The purpose of this retrospective study is to document the prognostic factors including different radiotherapy techniques in predicting outcome after lymph node block dissection and adjuvant RT in malignant melanoma patients with lymph node metastasis to a single nodal region.

Methods Patients receiving adjuvant radiotherapy following nodal block dissection between 1999 and 2011 were identified. The radiotherapy techniques used were reviewed. Outcome data collected for each technique identified included the rate of local recurrence, the site of local recurrence and the time to local recurrence. Progression-free and overall survival rates were calculated.

Results Forty-nine patients were identified. Seventeen were planned with conventional simulation and 32 with CTplanned radiotherapy either using virtual simulation or a planned volume technique. The majority of patients received
\end{abstract}

J. Sherriff $\cdot$ A. Zarkar

Hall-Edwards Radiotherapy Research Group, Cancer Centre,

Queen Elizabeth Hospital,

Birmingham, UK

\section{A. Martin-Clavijo}

Department of Dermatology, University Hospitals Birmingham

NHS Foundation Trust, Queen Elizabeth Hospital,

Birmingham, UK

\section{P. Nightingale}

University Hospitals Birmingham NHS Foundation Trust,

Queen Elizabeth Hospital,

Birmingham, UK

\section{J. Sherriff $(\bowtie)$}

Cancer Centre, Queen Elizabeth Hospital,

Edgbaston,

Birmingham B15 2TH, UK

e-mail: jennifer.sherriff@nhs.net either 50 or 48 Gy in 20 fractions over 4 weeks for disease with a high risk of post-operative local recurrence. The median follow-up was 35 (range 3-140)months in surviving patients. Local recurrence occurred in five $(29.4 \%)$, four $(25.0 \%)$ and two $(12.5 \%)$ of those treated with simulated, virtually simulated and conformal techniques, respectively. The median overall survival for all patients was 38.3 months, and the median progression-free survival was 26.6 months. Univariable analyses revealed that metastasis to 4 or more regional lymph node was a significant predictive factor for local recurrence $(p=0.004)$. Presence of extracapsular extension, involved or close margins or size of the largest nodes were not significant in predicting local recurrence.

Conclusion Although the difference between the local control rates did not reach statistical significance with the different radiation techniques, local control is maintained using conformal radiotherapy. As metastases to 4 or more regional lymph nodes were significantly associated with reduced control, improved strategy and techniques in radiation therapy to further improve local control are needed and require further investigation.

Keywords Nodal melanoma $\cdot$ Adjuvant radiotherapy

\section{Introduction}

The incidence of malignant melanoma in the UK has more than quadrupled over the last 30 years with approximately 11,770 new cases diagnosed in 2008 [1]. Nodal involvement or recurrence following resection of the original primary tumour is associated with a poor prognosis, with 5-year survival rates for patients with nodal micro-metastases and macro-metastases of just 67 and $43 \%$, respectively [2]. Furthermore, nodal disease can also lead to considerable morbidity and thus have a negative impact upon quality of life. 
The current standard management of melanoma spread to a single nodal group without evidence of other metastasis has been predominantly through a surgical approach. Despite the fact that surgeons have become more skilled at nodal block dissections, the prognosis following nodal recurrence remains poor. The role of adjuvant radiotherapy has yet to be fully established, but increasingly evidence suggests a benefit in terms of improving local control [3-5]. Consensus guidelines published in 2010 [6] suggest that the risks and benefits of adjuvant radiotherapy should be considered. If there is clinical or histological doubt about the adequacy of surgery following recurrence, or about the feasibility of salvage surgery, adjuvant radiotherapy may be considered.

The Trans-Tasman Radiation Oncology Group (TROG) has published a prospective trial of post-operative nodal irradiation for node-positive melanoma patients. Two hundred and thirty-four patients were treated with 48 Gy in 20 daily fractions to the nodal basin using conventionally planned radiotherapy. The in-field first recurrence rate was low at $6.8 \%$, after a median follow-up of just under 5 years. Radiotherapy was generally well tolerated with the main late toxicity being lymphoedema: grade 3 in $9 \%$ receiving axillary radiotherapy and $19 \%$ receiving ilio-inguinal radiotherapy [3]. More recently, a prospective trial has been undertaken, randomising 217 patients following lymphadenectomy to either adjuvant radiotherapy to a dose of $48 \mathrm{~Gy}$ in 20 daily fractions or observation only. After a median follow-up of just over 3 years, results suggest a significant improvement in local control with radiotherapy [5].

As advanced radiotherapy techniques become more widely available in routine practice, sparing of normal tissues becomes more possible to reduce toxicity. Conversely, smaller target and irradiated volumes lead to concerns regarding a possible increase in the rate of subsequent local recurrence. This has not previously been considered when irradiating nodal basins in the adjuvant setting for melanoma. Clearly, the benefits of reducing the risk of toxicity, for example lymphoedema, can only be beneficial if the newer radiotherapy technique does not compromise on local control.

The purpose of this study was to compare the different planning techniques used for adjuvant radiotherapy at one institution over the past decade to ensure that newer techniques with smaller irradiated volumes do not result in worse local control rates. In addition, other predictive factors for local failure after lymph node block dissection and adjuvant RT in this group of patients with single nodal group metastasis were studied.

\section{Methods}

Patients undergoing adjuvant radiotherapy following nodal block dissection for malignant melanoma between 1999 and
2011 were identified from an existing radiotherapy database. Baseline characteristics were assessed including the date and site of the original melanoma diagnosis if known, the Breslow thickness and presence or absence of ulceration, the site of nodal disease, the number and size of lymph nodes involved at the time of nodal surgery, the presence of extra-nodal spread and the distance to surgical margins. The type of nodal surgery performed and the radiotherapy technique and dose/fractionation schedules were reviewed. Radiotherapy was offered to patients deemed at high risk of local recurrence by the local multidisciplinary team meeting as discussed on an individual patient basis. This was based on a number of risk factors including the size and number of involved nodes found at block dissection, close or involved margins and the presence of extracapsular spread. Each patient was then counselled by a clinical oncologist as to the pros and cons of adjuvant radiotherapy, and an informed decision was made as to whether to undergo radiotherapy or not.

Radiotherapy techniques were divided into a conventional technique, i.e. planned using a simulator, or a computerised tomography (CT) planned technique. The CT-planned patients were further divided into those planned using a virtual simulation technique and those planned using a contoured volume. Field edges, as defined using simulation or virtual simulation, were defined as per the individual clinician treating the patient but overall covered the nodal region involved and the adjacent nodal group. The clinical target volume, for those contoured, was defined as the involved nodal basin, i.e. pathologically involved nodal basin with an appropriate margin to allow for microscopic spread along lymphatic drainage in the superior and inferior planes. While outlining the clinical target volume (CTV), consideration was given to pathological features such as extracapsular spread, macroscopic surgical clearance only, involved or close margin. This was grown isometrically to create a planning target volume (PTV). 3D conformal plans were then produced, using between three and six non-coplanar fields, to ensure adequate coverage of the target volume.

The primary outcomes were the local recurrence rate and the site of local recurrence in relation to the radiotherapy treated volume. These were identified for each radiotherapy technique used. Local recurrence was defined as recurrence occurring within the nodal group or groups treated with radiotherapy. In order to assess the location of recurrence in relation to the radiotherapy treated volume, CT images at the time of recurrence were compared to the original simulator fields, virtually simulated volumes or contoured volumes as defined at the time of radiotherapy planning. In case of difficulty identifying whether recurrences had occurred within or beyond the radiotherapy treated volume, the imaging at the time of recurrence was to be fused to the original planning CT (if CT planned) to allow proper assessment of the location of local recurrence with respect to the irradiated volume. 
Secondary outcomes included the time to local recurrence and the rate of distant recurrences comparing the different radiotherapy techniques. Progression-free and overall survival rates for all patients receiving adjuvant nodal radiotherapy were also calculated, using KaplanMeier analysis in PASW Statistics 18 (SPSS Inc., Chicago, IL, USA). Survival was measured from the date of nodal surgery until death or at the date last seen, with alive and non-relapsed patients being censored at date last seen alive and free of progression. Comparison of local recurrence rate was made between the techniques using the Tarone-Ware test. A subgroup analysis of potential prognostic factors which might impact on local recurrence rates was performed using the Tarone-Ware test. A combined outcome of death or local recurrence was used in order to avoid the assumptions that all those who died had local recurrence or that all local recurrence had been detected in advance of death. Any late radiation toxicities identified by a clinician during three to six monthly follow-up assessments were reviewed. The study was registered as an audit with the relevant hospital clinical governance committee (ref. CAD-03919-11).

\section{Results}

\section{Patient characteristics}

Forty-nine patients were identified undergoing adjuvant nodal radiotherapy between January 1999 and December 2011. Baseline characteristics including demographics, details of the original melanoma diagnosis if known and histological outcomes post-nodal surgery are shown in Table 1. The median age at diagnosis was 54 (range 18-88)years, and the median age at the time of nodal recurrence was 58 (range 18-89)years. Thirty-four patients were male and 15 were female in concordance with the male preponderance expected for melanoma. Thirty-eight patients had a confirmed diagnosis of melanoma prior to subsequently developing nodal recurrence. The median time to nodal recurrence from their original melanoma diagnosis was 14 (range 0-621)months. The remaining 11 patients presented with nodal melanoma in the absence of a previous history of melanoma. The majority of patients had undergone nodal block dissection (Table 2) prior to being offered radiotherapy.

\section{Radiotherapy}

Seventeen patients were planned with conventional simulation and 32 with CT-planned radiotherapy either using virtual simulation (16 cases) or a planned volume technique (16 cases). The median time from nodal surgery to radiotherapy was 2 (range 1-9)months for all patients: 3 for the simulated group, 2 for the virtual simulated group and 2 for the conformally planned group. A number of different radiotherapy schedules were used over the 12-year period during which patients were treated. Table 3 shows the dose/fractionation schedules used in relation to the planning technique used. The majority of patients received either 50 or $48 \mathrm{~Gy}$ in 20 fractions over 4 weeks for disease with a high risk of post-operative local recurrence. All patients completed their radiotherapy schedule without delay or gaps apart from one patient whose treatment was stopped early after they developed progressive disease with widespread subcutaneous metastases.

\section{Treatment outcome}

At the time of last follow-up, 20 patients had died, 19 were alive and relapse free and the remaining 10 were alive following distant relapse. The median follow-up was 35 (range 3-140)months in surviving patients. The median overall survival for all patients was 38.3 months, and the median progression-free survival was 26.6 months. Figures 1 and 2 illustrate Kaplan-Meier curves for overall and progression-free survival, respectively.

Local recurrence occurred in 11 of the $49(22.4 \%)$ patients who completed adjuvant radiotherapy to the nodal basin. This included local recurrences in five $(29.4 \%)$, four $(25.0 \%)$ and two $(12.5 \%)$ of those treated with simulated, virtually simulated and conformal techniques, respectively. No significant difference was seen in the local recurrence rates between the simulated/virtually simulated and conformally treated patients (nine local recurrences from 33 patients vs. two local recurrences from 16 patients; $p=$ 0.88 ). There were smaller numbers and a shorter median follow-up in surviving patients in the conformal group compared to the simulated/virtually simulated groups (10 vs. 61 months). Of the five patients with local recurrence planned using the simulator: two developed in-field nodal recurrence, one out of field recurrence in an adjacent nodal group and two developed subcutaneous metastases. Of the four treated using virtual simulation, all four developed infield nodal recurrence, and of the two planned using a conformal technique, one developed subcutaneous metastases and one developed in-field nodal recurrence. Fusion of the radiotherapy fields/volume to images at the time of local recurrence was not required in any of the patients studied as there were no cases where the site of recurrence was marginal, i.e. at the edge of the irradiated volume.

The median time to local recurrence was $7(0-46)$ months for all patients and 21, 4.5 and 6 for the simulated, virtually simulated and planned volume radiotherapy groups, respectively. Twenty-six patients $(53.1 \%)$ went onto develop distant recurrence; 16 of these patients had died and ten were still alive at the time of last follow-up. Four of the 23 not documented to have developed distant recurrence had 
Table 1 Patient demographics and tumour characteristics

\begin{tabular}{|c|c|c|c|c|}
\hline & All patients (49) & $\begin{array}{l}\text { Simulation } \\
\text { technique (17) }\end{array}$ & $\begin{array}{l}\text { Virtual simulation } \\
\text { technique (16) }\end{array}$ & $\begin{array}{l}\text { Planned volume } \\
\text { technique (16) }\end{array}$ \\
\hline Median age at diagnosis (years) & $54(18-88)$ & $59.5(33-75)$ & $49.4(18-88)$ & $54.9(31-75)$ \\
\hline \multicolumn{5}{|l|}{ Gender } \\
\hline Male & $34(69.4 \%)$ & $11(64.7 \%)$ & $13(81.3 \%)$ & $10(62.5 \%)$ \\
\hline Female & $15(30.6 \%)$ & $6(35.3 \%)$ & $3(18.7 \%)$ & $6(37.5 \%)$ \\
\hline \multicolumn{5}{|l|}{ Type of melanoma } \\
\hline Superficial spreading & $11(22.4 \%)$ & $4(23.6 \%)$ & $2(12.5 \%)$ & $5(31.3 \%)$ \\
\hline Nodular & $13(26.6 \%)$ & $5(29.4 \%)$ & $4(25.0 \%)$ & $4(25.0 \%)$ \\
\hline Lentigo maligna & $5(10.2 \%)$ & $3(17.6 \%)$ & $2(12.5 \%)$ & 0 \\
\hline Acral lentiginous & $2(4.1 \%)$ & $1(5.9 \%)$ & 0 & $1(6.2 \%)$ \\
\hline Desmoplastic & $2(4.1 \%)$ & 0 & $2(12.5 \%)$ & 0 \\
\hline Other (e.g. conjunctival, head and neck etc) & $5(10.2 \%)$ & $1(5.9 \%)$ & $3(18.75 \%)$ & $1(6.2 \%)$ \\
\hline Unknown & $11(22.4 \%)$ & $3(17.6 \%)$ & $3(18.75 \%)$ & $5(31.3 \%)$ \\
\hline $\begin{array}{l}\text { Median Breslow thickness of primary } \\
\text { melanoma }(\mathrm{mm})\end{array}$ & $2.5(0.1-9.5)$ & $3.85(0.1-9.5)$ & $4.13(0.1-9)$ & $4.23(0.4-9)$ \\
\hline \multicolumn{5}{|l|}{ Ulceration } \\
\hline Yes & $13(26.5 \%)$ & $7(41.2 \%)$ & $2(12.5 \%)$ & $4(25.0 \%)$ \\
\hline No & $12(24.5 \%)$ & $3(17.6 \%)$ & $4(25.0 \%)$ & $5(31.3 \%)$ \\
\hline Unknown & $24(49.0 \%)$ & $7(41.2 \%)$ & $10(62.5 \%)$ & $7(43.7 \%)$ \\
\hline \multicolumn{5}{|l|}{ Nodal site/site of RT } \\
\hline Head and neck & $16(32.7 \%)$ & $8(47.1 \%)$ & $7(43.7 \%)$ & $1(6.2 \%)$ \\
\hline Axilla & $19(38.8 \%)$ & $5(29.4 \%)$ & $5(31.3 \%)$ & $9(56.3 \%)$ \\
\hline Ilio-inguinal & $14(28.5 \%)$ & $4(23.5 \%)$ & $4(25.0 \%)$ & $6(37.5 \%)$ \\
\hline \multicolumn{5}{|l|}{ Median no. of nodes } \\
\hline Resected & $16(0-46)$ & $15(7-33)$ & $23(9-46)$ & $19(1-39)$ \\
\hline Positive & $2(0-21)$ & $2(1-7)$ & $7(1-21)$ & $4(1-16)$ \\
\hline \multicolumn{5}{|l|}{ Extracapsular extension } \\
\hline Yes & $38(77.6 \%)$ & $13(76.4 \%)$ & $11(68.75 \%)$ & $14(87.5 \%)$ \\
\hline No & $5(10.2 \%)$ & $2(11.8 \%)$ & $3(18.75 \%)$ & 0 \\
\hline Unknown & $6(12.2 \%)$ & $2(11.8 \%)$ & $2(12.5 \%)$ & $2(12.5 \%)$ \\
\hline \multicolumn{5}{|l|}{ Size of largest node } \\
\hline$\leq 3 \mathrm{~cm}$ & $13(26.5 \%)$ & $8(47.0 \%)$ & $3(18.7 \%)$ & $2(12.5 \%)$ \\
\hline$>3 \mathrm{~cm}$ & $25(51.0 \%)$ & $3(17.7 \%)$ & $8(50.0 \%)$ & $14(87.5 \%)$ \\
\hline Unknown & $11(22.5 \%)$ & $6(35.3 \%)$ & $5(31.3 \%)$ & 0 \\
\hline \multicolumn{5}{|l|}{ Margins } \\
\hline Involved & $9(18.4 \%)$ & $1(5.9 \%)$ & $8(50.0 \%)$ & 0 \\
\hline 'Close' & $6(12.2 \%)$ & 0 & $2(12.5 \%)$ & $4(25.0 \%)$ \\
\hline$\leq 1 \mathrm{~mm}$ & $14(28.6 \%)$ & $5(29.4 \%)$ & $1(6.25 \%)$ & $8(50.0 \%)$ \\
\hline $1-2 \mathrm{~mm}$ & $4(8.2 \%)$ & 0 & $1(6.25 \%)$ & $3(18.75 \%)$ \\
\hline $2-5 \mathrm{~mm}$ & $1(2.0 \%)$ & 0 & 0 & $1(6.25 \%)$ \\
\hline 'Clear' (>5 mm) & $9(18.4 \%)$ & $5(29.4 \%)$ & $4(25.0 \%)$ & 0 \\
\hline Unknown & $6(12.2 \%)$ & $6(35.3 \%)$ & 0 & 0 \\
\hline
\end{tabular}

died at the time of data collection. All of the 11 with local recurrence developed distant recurrence either alongside the local recurrence or subsequently. Further treatments offered included further surgical resection, palliative chemotherapy with dacarbazine, ipilumumab, clinical trial entry or palliative care.
Prognostic factors for local control

Univariable subgroup analysis considering potential prognostic factors for local recurrence, using the combined outcome of local recurrence or death, was performed. This revealed that patients with four or more nodes involved were 
Table 2 Type of nodal resection performed

\begin{tabular}{lllll}
\hline & All patients & Simulation technique & Virtual simulation technique & Planned volume technique \\
\hline Excision only & 4 & 1 & 3 & 0 \\
Nodal block dissection & 45 & 16 & 13 & 16 \\
\hline
\end{tabular}

significantly more likely to develop local recurrence (Tarone-Ware $p=0.004)$. No significant increase in the rate of local recurrence was found with the presence of extracapsular extension, involved or close margins or size of the largest node (Tarone-Ware $p=0.205,0.574,0.085$, respectively). No other significant prognostic factors were identified for either local control or survival

\section{Adverse effects}

Of the 49 patients treated, six were documented to have developed lymphoedema during their follow-up period, one developed wound breakdown requiring a skin graft and one developed hearing loss following radiotherapy to the left neck.

\section{Radiobiology}

Table 3 shows the dose/fractionation schedules used and calculated biological effective dose (BED) for each using an alpha-beta ratio of 2.5. This has been estimated in a radiobiological review considering over 600 irradiated malignant melanomas [7]. The overall mean BED was $94.7 \mathrm{~Gy}$, with mean BEDs of 91.2, 98.6 and 94.4 Gy for those planned using the simulator, virtual simulation and conformal planning, respectively. For those developing local recurrence, the overall mean BED was $92.8 \mathrm{~Gy}$, with mean BEDs are 90.4, 97.2 and 89.8 Gy for those planned using the simulator, virtual simulation and conformal planning, respectively. No significant difference in BED was found between the groups who went on to develop local recurrence compared to the groups who did not develop local recurrence (all patients: $p=0.426$, simulation group: $p=0.657$, virtual simulation group: $p=1.00$ and conformal group: $p=0.242$ using the Mann-Whitney test).

\section{Discussion}

The role of adjuvant radiotherapy after nodal block dissection for malignant melanoma remains controversial. The risk of systemic recurrence and hence a poor prognosis remains high in this group of patients. Adjuvant radiotherapy has historically been avoided because of concerns over both acute toxicity and the high risk of subsequent lymphoedema, resulting in a detrimental effect on quality of life.

Recently published data have, however, suggested that radiotherapy may have a role to play in reducing the risk of local recurrence [5]. The results presented here are consistent with this and with another similar retrospective review [8]. This retrospective review considered 42 patients treated with adjuvant radiotherapy, planned using a conventional technique, with the majority receiving a dose of 50 Gy in 2 Gy fractions. The rate of local recurrence was approximately $19 \%$ in a cohort similar to that studied here using a radiotherapy dose/fractionation schedule similar to those given in this cohort. Table 4 shows a comparison of the results presented here with results previously published.

Little data currently exist for the use of more advanced radiotherapy techniques, such as intensity modulated radiotherapy (IMRT) in the adjuvant setting for nodal melanoma.

Table 3 Radiotherapy dose/fractionation schedules

\begin{tabular}{|c|c|c|c|c|c|}
\hline $\begin{array}{l}\text { Dose/ } \\
\text { fractionation }\end{array}$ & $\begin{array}{l}\text { Biological equivalent } \\
\text { dose } \alpha \beta \text { ratio }=2.5^{7}\end{array}$ & All (49) & $\begin{array}{l}\text { Simulation } \\
\text { technique (17) }\end{array}$ & $\begin{array}{l}\text { Virtual simulation } \\
\text { technique (16) }\end{array}$ & $\begin{array}{l}\text { Planned volume } \\
\text { technique (16) }\end{array}$ \\
\hline $50 \mathrm{~Gy} / 20 \#$ & 100 & $22(44.9 \%)$ & $7(41.2 \%)$ & $10(62.5 \%)$ & $5(31.25 \%)$ \\
\hline 48 Gy/20\# & 94.08 & $9(18.4 \%)$ & 0 & 0 & $9(56.25 \%)$ \\
\hline 45 Gy/20\# +10 Gy/5\# & 103.4 & $3(6.1 \%)$ & 0 & $3(18.75 \%)$ & 0 \\
\hline 45 Gy/25\# & 77.4 & $3(6.1 \%)$ & $2(11.8 \%)$ & 0 & $1(6.25 \%)$ \\
\hline 45 Gy/20\# & 85.5 & $5(10.3 \%)$ & $3(17.5 \%)$ & $1(6.25 \%)$ & $1(6.25 \%)$ \\
\hline $40 \mathrm{~Gy} / 15 \#$ & 82.7 & $2(4.1 \%)$ & $1(5.9 \%)$ & $1(6.25 \%)$ & 0 \\
\hline $55 \mathrm{~Gy} / 25 \#$ & 103.4 & $1(2.0 \%)$ & $1(5.9 \%)$ & 0 & 0 \\
\hline 52.5 Gy $/ 20 \#$ & 107.6 & $2(4.1 \%)$ & $2(11.8 \%)$ & 0 & 0 \\
\hline $50 \mathrm{~Gy} / 25 \#+10 \mathrm{~Gy} / 5 \#$ & 108 & $1(2.0 \%)$ & 0 & $1(6.25 \%)$ & 0 \\
\hline $24 \mathrm{~Gy} / 16 \#$ & 38.4 & $1(2.0 \%)$ & $1(5.9 \%)$ & 0 & 0 \\
\hline
\end{tabular}


Fig. 1 Overall survival for all patients

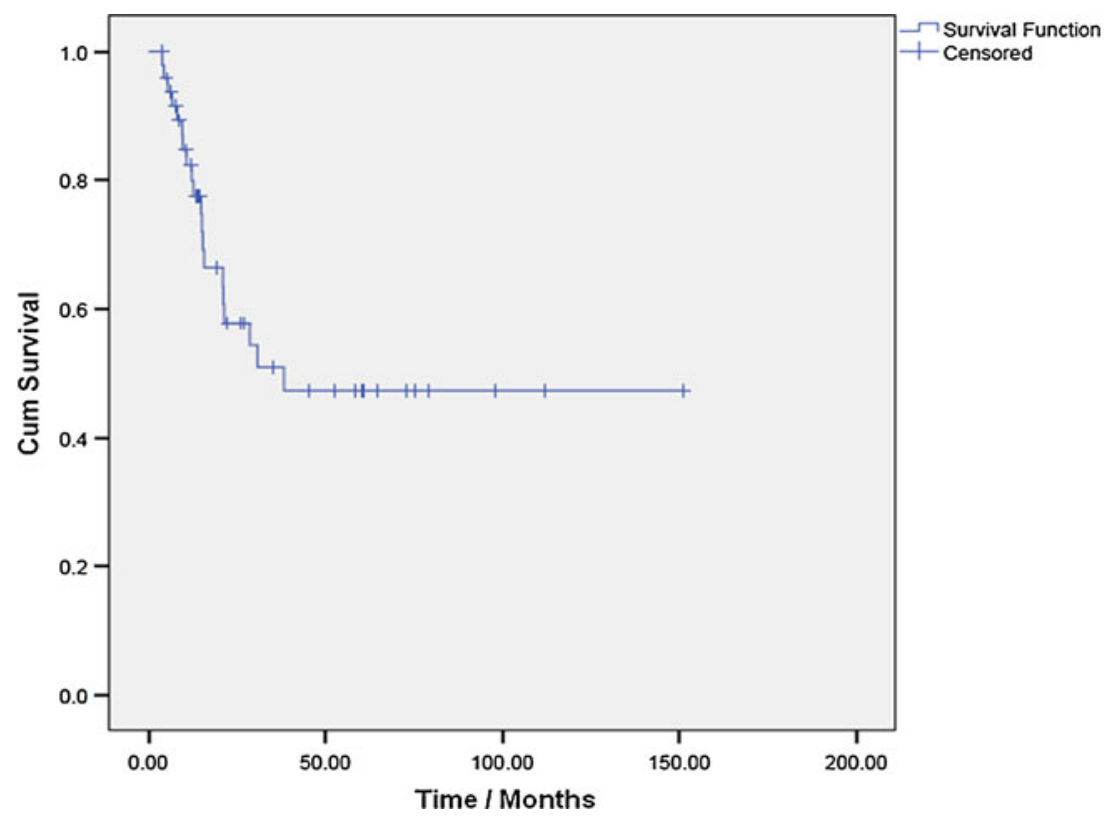

The TROG study group have previously defined standardised radiation fields for simulated or virtually simulated nodal irradiation, and the technique for the prospective phase II study considering adjuvant post-operative radiation therapy following nodal surgery in malignant melanoma was published in 2006 [3]. To date, no guidance exists as to how to define target volumes for conformal radiotherapy or IMRT in the adjuvant setting following nodal block dissection. As access to advanced techniques increases, it will become crucial to assess patient outcomes in terms of local recurrence rates, survival and also toxicity rates, to see if treatments using these valuable resources are clinically and cost-effective for patients. This needs to be studied in a large prospective trial.

The progression-free and overall survival figures seen within this cohort are consistent with that expected for stage III melanoma patients. Over the decade during which these patients were treated, advances in treatment for systemic melanoma have occurred with relatively little improvement in mortality rates. This is reflected in the poor survival seen in this group as a whole. To date, no evidence has been found to suggest that adjuvant radiotherapy has any effect on overall survival from melanoma. In the 1970s, Creagan et al. randomized 82 patients between radiotherapy and
Fig. 2 Progression-free survival for all patients

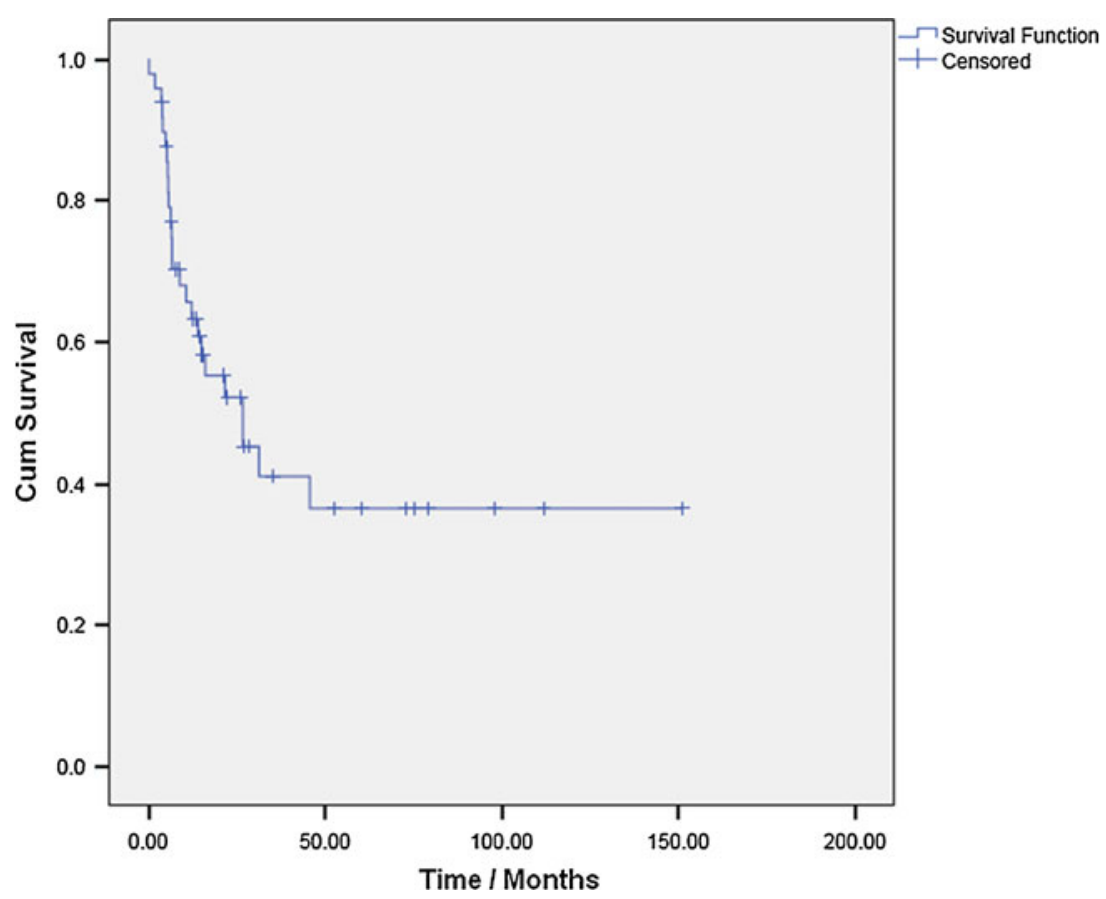


Table 4 Comparison against published studies

\begin{tabular}{|c|c|c|c|c|c|}
\hline Study & $\begin{array}{l}\text { Number of } \\
\text { patients }\end{array}$ & $\begin{array}{l}\text { Radiotherapy } \\
\text { dose }\end{array}$ & $\begin{array}{l}\text { Radiotherapy } \\
\text { technique }\end{array}$ & $\begin{array}{l}\text { Median follow-up } \\
\text { (months) }\end{array}$ & $\operatorname{LR}(\%)$ \\
\hline This study & 49 & $\begin{array}{l}\text { Majority } 48-50 \mathrm{~Gy} / 20 \# \\
\text { (see Table 3) }\end{array}$ & $\begin{array}{l}\text { Simulation/virtual simulation/ } \\
\text { conformal (see text) }\end{array}$ & 35 & 22.4 \\
\hline $\begin{array}{l}\text { Burmeister et al. } \\
\text { TROG } 96.06 \text { [3] }\end{array}$ & 230 & $45-50$ Gy in $20-21 \#$ & $\begin{array}{l}2-3 \text { field technique using photons } \\
\text { or applied electron field for } \\
\text { selected head and neck cases }\end{array}$ & 58.4 & 6.8 \\
\hline $\begin{array}{l}\text { Burmeister et al. } \\
\text { TROG } 02.01 / \\
\text { ANZMTG } \\
01.02[5]\end{array}$ & 109 & $48 \mathrm{~Gy} / 20 \#$ & $\begin{array}{l}\text { 2-3 field technique using } \\
\text { photons or applied electron } \\
\text { field for selected head and } \\
\text { neck cases }\end{array}$ & 40 & 18 \\
\hline Corry et al. [8] & 42 & 50 Gy (range $30-60 \mathrm{~Gy}$ ) in $25 \#$ & $\begin{array}{l}2-3 \text { field technique using photons } \\
\text { or applied electron field for } \\
\text { selected head and neck cases }\end{array}$ & 72 & 19 \\
\hline Ballo et al. [9] & 466 & $\begin{array}{l}30 \text { Gy delivered twice weekly at } \\
6 \mathrm{~Gy} / \# \text { over } 2.5 \text { weeks }\end{array}$ & $\begin{array}{l}\text { Anterior-posterior opposed } \\
\text { photon or electron fields }\end{array}$ & 50.4 & 11 \\
\hline
\end{tabular}

observation after lymphadenectomy for melanoma. The radiotherapy was given with anterior and posterior opposed fields to an initial dose of 25 Gy in 14 daily fractions, followed by a 4-week break, and then a further $25 \mathrm{~Gy}$ in 14 fractions. Once differences between the two groups were accounted for, no significant differences were found in overall and disease-free survival rates [10]. This may simply reflect the aggressive nature of this disease and the fact that by the time nodal recurrences are occurring, the melanoma is already a systemic disease destined to progress even if local nodal recurrence can be prevented. This would suggest that perhaps a combination of adjuvant radiotherapy and systemic therapy should be the focus of future efforts to improve outcomes from stage III melanoma.

Little published data are currently available to define prognostic factors which impact on local control within this setting of patients with melanoma following nodal surgery and adjuvant radiotherapy. Prior to the use of adjuvant radiotherapy, the following prognostic factors have been identified as having an impact on local control: extra-nodal spread, number and size of the lymph nodes involved and metastases located in the cervical nodal basin [11]. In contrast, a prospective study of adjuvant radiotherapy, identified extra-nodal spread as an independent risk factor for lymph-node field relapse but lymph-node field site (head and neck, axilla or groin), status of primary lesion (known or unknown primary) and number of positive nodes (one, two or three, or four or more) failed to show any significant impact on local control rates [5]. The majority of patients included within this trial were deemed to be at high risk of local recurrence and hence had, on average, a high number of nodes involved. The mean numbers of nodes involved were 1.93, 3.96 and 3.66 for head and neck, axilla and groin irradiated sites, respectively. As such, the prognostic factor of number of nodes was already accounted for within the study population, and so no significant impact on local recurrence rate was observed.
The current adjuvant radiotherapy study identifies the number of lymph nodes involved as a prognostic factor for local control, with a significant increase in the observed local recurrence rates if four or more nodes are involved. There is now a need to consider strategies to reduce the risk of local recurrence in heavily node positive patients, such as those with four or more nodes involved. An example of this would be to assess the role of radiotherapy dose escalation in the adjuvant setting. This is becoming ever more possible with the introduction of more advanced radiotherapy techniques, such as IMRT.

There remains concern amongst skin oncology groups about the benefits of adjuvant radiotherapy following nodal block dissection in melanoma patients with limited metastasis to a single nodal group. As large randomized trials on adjuvant RT are hard to undertake successfully, it is essential that all patients opting to receiving adjuvant RT are closely followed up. If improved local control can be achieved with the use of adjuvant RT with acceptable toxicity, further improvement in survival may be observed with longer follow-up. Nevertheless, the retrospective nature of a study such as this report will always serve as a limitation.

The BED is consistently lower across all three radiotherapy techniques in the groups who go on to develop local recurrence, although the numbers are too small to reveal a significant difference. This suggests that a BED of at least 95 Gy is necessary in order to optimise local control. Larger numbers are needed to conclusively demonstrate this and future studies considering dose escalation should be considered using newer radiotherapy techniques, as long as toxicity levels remain acceptable.

\section{Conclusions}

The rates of local recurrence following adjuvant radiotherapy post-nodal block dissection for melanoma are maintained 
with the use of conformal compared to conventional radiotherapy techniques. Patterns of local recurrence should be continually assessed with the introduction of more advanced radiotherapy techniques, alongside radiotherapy toxicity and quality of life. Consensus guidelines to define the CTV and PTV when irradiating nodal basins post-operatively using CT-planned radiotherapy need to be defined.

Conflicts of interest The authors declare that they have no conflict of interest.

\section{References}

1. CancerStats Key Facts (2012) Skin cancer. Cancer Research UK, London

2. Balch CM, Gershenwald JE, Soong SJ, Thompson JF, Ding S, Byrd DR, Cascinelli N, Cochran AJ, Coit DG, Eggermont AM, Johnson T, Kirkwood JM, Leong SP, McMasters KM, Mihm MC Jr, Morton DL, Ross MI, Sondak VK (2010) Multivariate analysis of prognostic factors among 2,313 patients with stage III melanoma: comparison of nodal micrometastases versus macrometastases. J Clin Oncol 28:2452-2459

3. Burmeister BH, Mark Smithers B, Burmeister E, Baumann K, Davis S, Krawitz H, Johnson C, Spry N, Trans Tasman Radiation Oncology Group (2006) A prospective phase II study of adjuvant postoperative radiation therapy following nodal surgery in malignant melanoma-Trans Tasman Radiation Oncology Group (TROG) Study 96.06. Radiother Oncol 81(2):136-142
4. Burmeister B, Henderson M, Thompson J, Fisher R, Di Iulio J, Smithers M, Hong A, Carruthers S, Hoekstra H, Ainslie J (2009) Adjuvant radiotherapy improves regional (lymph node field) control in melanoma patients after lymphadenectomy: results of a randomised trial (TROG 02.01/ANZMTG 01.02). Int J Rad Onc Biol Phys 75(3):S2

5. Burmeister BH, Henderson MA, Ainslie J, Fisher R, Di Iulio J, Smithers BM, Hong A, Shannon K, Scolyer RA, Carruthers S, Coventry BJ, Babington S, Duprat J, Hoekstra HJ, Thompson JF (2012) Adjuvant radiotherapy versus observation alone for patients at risk of lymph-node field relapse after therapeutic lymphadenectomy for melanoma: a randomised trial. Lancet Oncol 13:589-597

6. Marsden JR, Newton-Bishop JA, Burrows L, Cook M, Corrie PG, Cox NH, Gore ME, Lorigan P, MacKie R, Nathan P, Peach H, Powell B, Walker C (2010) Revised U.K. guidelines for the management of cutaneous melanoma 2010. Br J Dermatol 163(2):238-256

7. Overgaard J (1986) The role of radiotherapy in recurrent and metastatic malignant melanoma: a clinical radiobiological study. Int J Radiat Oncol Biol Phys 12(6):867-872

8. Corry J, Smith JG, Bishop M, Ainslie J (1999) Nodal radiation therapy for metastatic melanoma. Int J Radiat Oncol Biol Phys 44 (5):1065-1069

9. Ballo MT, Ross MI, Cormier JN, Myers JN, Lee JE, Gershenwald JE, Hwu P, Zagars GK (2006) Combined-modality therapy for patients with regional nodal metastases from melanoma. Int $\mathrm{J}$ Radiat Oncol Biol Phys 64(1):106-113

10. Creagan ET, Cupps RE, Ivins JC et al (1978) Adjuvant radiation therapy for regional nodal metastases from malignant melanoma: a randomized, prospective study. Cancer 42(5):2206-2210

11. Guadagnolo BA, Zagars GK (2009) Adjuvant radiation therapy for high-risk nodal metastases from cutaneous melanoma. Lancet Oncol 10:409-416 